\title{
Neurotrophins in Neuroendocrine Control: Brain Derived-neurotrophic Factor (BDNF) and Somatostatin Involvement in the Stress Response and Reproductive Physiology
}

\section{Contents}

Abstract

Introduction

Stress and Ovarian Hormone Interactions

Conclusion

BDNF, a Neurotrophin Involved in the Stress Response

Conclusion

Plasticity and Neurohormonal Release

BDNF in Astrocytes

BDNF in Tanycytes and Nerve Endings

Stress Stimulus

Conclusion

Acknowledgements

References

\section{Abstract}

Some neurohormonal secretions, other than Gn-RH, are also sensitive to gonadal steroid influences. Thus, we have recently shown that somatostatin (SRIH) is a hypothalamic hormone whose mRNA, peptide content and release are affected by the sexual cycle in vitro and in vivo. Furthermore, the in vivo interaction between stress application (cold exposure) and steroid status determines the subsequent response to a depolarizing concentration of $\mathrm{K}^{+}$analyzed in hypothalamic ex-vivo fragments. Such interaction between

\section{Correspondence}

Sandor Arancibia

Université de Montpellier 2, France.

FRE 2693 du CNRS

E-mail: sandor@univ-montp2.fr

Financial Support: "Region Languedoc-Roussillon" (France, Grant FDG/CS n 130, LT-A) and "Fondation Simone et Cino del Duca" (France, SA and LT-A). 
stress and sex steroids suggests that a kind of neuronal plasticity occurs to ensure this coupling process. We therefore focused on the brain derived-neurotrophic factor (BDNF), a conspicuous member of the neurotrophin NGF family that has been associated with synaptic plasticity and whose concentration is particularly important in the hypothalamus. In this region, we have shown that BDNF mRNA levels exhibit very rapid up-regulation following stress application and that protein translation also occurs rapidly. Under acute stress immobilization conditions, somatostatin expressing neurons are subjected to plasticity processes since somatostatin mRNA levels, measured by in situ hybridization (ISH), are increased in spite of a significant decrease in the number of cells expressing the messenger. In this connection, we observed that in the periventricular nucleus BDNF mRNA is likely localized in the same cells expressing somatostatin mRNA and are reactive to stress stimulus. Furthermore, in primary cultures of hypothalamic neurons, BDNF is able to stimulate both the synthesis and release of somatostatin. In addition, acute icv microinjections of BDNF are able to rapidly decrease somatostatin content in the hypothalamus, and this is also observed after acute stress application. This phenomenon could be explained by a concomitant increase in somatostatin release as estimated with push-pull cannula. The median eminence (ME) is another hypothalamic region where we have detected BDNF protein by immunohistochemical methods, particularly in astrocytes. In this structure, tanycytes (long considered to be indirect regulators of neurohormonal secretion in processes such as lactation and ovulation), appear to be a novel target of BDNF, since we detected the specific trkB receptor on the podia of these specialized glial cells. Furthermore, in this structure, BDNF content and release as well as $\operatorname{TrkB}$ receptors are sensitive to immobilization stress. Taken as a whole, these data indicate that there are close relationships between stress and sexual status, with hypothalamic somatostatin neurons being new cellular targets whose metabolism seems to be modulated by neurotrophins.

Key-words: BDNF, somatostatin, neuronal plasticity, steroids, stress, tanycyte cells.

Invited Full-review

\section{Introduction}

Neurotrophins represent a group of molecules having the nerve growth factor (NGF) as prototype which was long ago discovered by Levi-Montalcini (1960). These molecules (Leibrock et al., 1989) are involved in a variety of forms of synaptic plasticity in the central nervous system CNS (Thoenen, 1995, McAllister et al., 1999). They play an important role in the survival and differentiation of developing neurons but their role is less clear in the adult central nervous system and particularly in the hypothalamus. Their effects are mediated through specific high affinity receptors associated with tyrosine kinase activity (TrkA, B and C) and also through the unselective low affinity p75 neurotrophin receptor. Upon ligand binding, Trk receptors dimerize and become catalytically active, resulting in autophosphorylation. 
The brain-derived neurotrophic factor (BDNF) is a member of the neurotrophin family involved in synaptic plasticity (Thoenen, 1995) exerted through TrkB receptors (Glass \& Yancopoulos, 1993). mRNA encoding BDNF receptors generates at least three alternative splicing isoforms: one isoform encodes the full-length $\operatorname{TrkB}$ receptor (TrkB.FL) which has intrinsic tyrosine kinase activity. The other two isoforms encode truncated receptors (TrkB.T1 and TrkB.T2) lacking the kinase domain and containing intracellular domains of only 23 and 22 amino acids, respectively. TrkB.FL is expressed in neurons and it is the predominant isoform expressed during embryogenesis. TrkB.T1 is expressed in neurons and glial cells and is the major isoform expressed in the adult brain. Its expression is markedly induced at the time when axons reach targets or in glial cells after lesions. TrkB.T2 mRNA is weekly expressed in brain neurons. The ratio between the truncated and full-length forms seems to be essential to determine some biological actions of BDNF (Baxter et al., 1997).

The BDNF gene is complex, containing four 5' exons with distinctive promoters that are used to generate four types of transcripts (Timmusk et al., 1993) and one 3' exon. In addition, there are two alternative polyadenylation sites that give rise to eight different BDNF mRNAs. These transcripts are spliced to a common exon: the 3' exon that codes for the same mature BDNF peptide. The activation of different BDNF promoters seems to be region-specific and dependent on the type of brain insult (Kokaia et al., 1994) thus representing a particular kind of physiological regulation (Chew, 1997).

The hypothalamus is one of the brain regions containing the highest levels of BDNF mRNA (Conner et al., 1997) and BDNF peptide (Nawa et al., 1995). A wide distribution of TrkB receptors has also been shown in this region (Yan et al., 1994). In this region, we (Marmigère et al., 1998; Aliaga et al., 2002; Rage et al., 2002) and others (Smith et al., 1995; Castren et al., 1995) have reported a punctuated distribution of BDNF mRNA and protein in several hypothalamic nuclei and postulated a role in processes such as stress, which requires a high degree of plasticity. Neuronal plasticity is an important property characterizing the functional state of adult rat brain (Hatton, 1997). In the endocrine hypothalamus, plasticity has notably been studied in the supraoptic nucleus (SON) (Hatton, 1990), periventricular nucleus (PeVN) (Bhatnagar, 1999; Arancibia et al., 2000a) and paraventricular nucleus (PVN) (Watts, 1996; Itoi et al., 1999).

Nowadays, some clever definitions for the plasticity concept have been popularised, mainly that of Thoenen in 1995, stating that plasticity "is the capacity of neurons or glial cells to improve or to depress the synaptic efficacy through biochemical or morphological changes which evolve in a dynamical fashion." Some authors have coined the term "metaplasticity" to define the changes induced by synaptic or cellular activity that are not necessarily expressed as a change in the efficacy of normal synaptic transmission, but rather as changes in the ability to induce subsequent synaptic plasticity (Abraham \& Tate, 1997). Metaplastic changes will therefore affect the synaptic or cellular physiology in such a way that subsequent attempts to induce traditional synaptic plasticity 
will be substantially modified. In this sense, the term "meta" plasticity refers to plasticity at a different or higher level. Stress is one of the most relevant metaplastic stimuli because, in addition to its "metaplastic" action (Kim \& Yoon, 1998), it is also able to modify per se the neuronal plasticity. It is widely known that organisms are often subject to stressors which disrupt homeostasis. Homeostasis refers to the preservation of a narrow range of vital physiological parameters necessary for survival $(\mathrm{pH}$; body temperature and oxygen tension). Systemic stress is a relatively imprecise concept that we can define as any external or internal disturbing challenge that overcomes the adaptation capacities of an organism, which triggers a succession of mechanisms that re-establish homeostasis. Stressors thus trigger the activation of neural and endocrine adaptations that form the stress-response, originally formulated by Selye in the 30's as the "General Adaptation Syndrome". Indeed, two major adaptive changes occur after stress exposure: (i) on the one hand, the activation of a sympathetic pathway resulting in enhanced secretion of catecholamines, epinephrine and norepinephrine, and, (ii) on the other hand, the activation of the endocrine pathway, represented by adrenal secretion of glucocorticoids which are secreted as the final step in an endocrine cascade beginning with the perception of one stressor by the brain. The hypothalamus secretes a variety of neurohormones within seconds but essentially, the corticotropin releasing hormone (CRH) and vasopressin (AVP). These hormones enter the portal circulation, are carried to its cell targets on the anterior pituitary to rapidly stimulate adrenocorticotropic hormone (ACTH) release. This extremely rapid process is observed within approximately $15 \mathrm{~s}$. ACTH then acts upon the adrenal cortex to facilitate the synthesis and release of glucocorticoids within some minutes. Adrenal hormones, namely cortisol in humans and corticosterone in rodents, are extremely useful since they supply the cellular energy required to cope with stress. Then, to prevent hyper-excitation of the hypothalamic-pituitary-adrenal (HPA) axis, glucocorticoids (GC) will subsequently exert negative feed-back upon the hippocampus, the hypothalamus and the anterior pituitary (Jacobson \& Sapolsky, 1991).

However, besides the HPA axis, other endocrine functions are also affected by stress. Concerning the reproductive physiology, for instance, it must be kept in mind that a decline in portal GnRH concentrations and pituitary release of gonadotropins occurs within minutes after the onset of a stressor, thus inhibiting the reproductive physiology and behavior. It is known that when individuals undergo a stress situation, one of the first events occurring in the central nervous system (CNS) is a significant decrease in the secretion of $\mathrm{GnRH}$, the hypothalamic hormone controlling the reproductive physiology (Kam et al., 2000; Dobson et al., 2003). Hence, stress is clearly an important factor that can inhibit the reproductive function in mammals.

In the rat, acute and chronic stress suppresses growth hormone $(\mathrm{GH})$ secretion largely by increasing somatostatin release. Somatostatin, the hypothalamic inhibitory hormone that essentially controls GH (Brazeau et al., 1973), also modulates other secretions from the pituitary gland, such as the thyretrope stimulating hormone (TSH) (Vale et al., 
1974) and prolactin (PRL) (Enjalbert et al., 1982), but interestingly a particular modulation of the HPA axis is also exerted by somatostatin on the basis of functional or morphological connections between $\mathrm{CRH}$ and somatostatin neurons. Light and electronic microscopic studies coupled to double immunostaining for $\mathrm{CRH}$ and for somatostatin revealed the presence of reciprocal synaptic relations between neurons containing immunoreactive $\mathrm{CRH}$ and those containing somatostatin in the anterior periventricular area (Hisano \& Daikoku, 1991). In addition, physiological data showed a functional link between CRH and somatostatin neuronal systems in the control of ACTH and GH secretion from the pituitary (Rivier \& Vale, 1985). Likewise, it has been reported that injections of CRH antibodies into the third ventricle, besides blocking the ACTH response to stress, also block the decrease of plasma GH in response to ether stress (Ono et al., 1985). Injections of somatostatin or its analogues into the third ventricle of rats inhibit stress-induced ACTH secretion by attenuating endogenous CRH release (Brown et al., 1984). On the other hand, a stimulatory effect of $\mathrm{CRH}$ on somatostatin release in vitro and in vivo have also been demonstrated (Mitsugi et al., 1990). Taken together, these results show close interactions between $\mathrm{CRH}$ and somatostatin secretory neurons and thereby somatostatin seems to be a hypothalamic hormone strongly involved in stress responses. In rats, somatostatin release from the median eminence is strongly modified in response to all kinds of stressors studied, just when rapid physiological responses are needed, e.g. after electric shock (Arimura et al., 1976), forced swimming (Terry et al., 1976), starvation (Tannenbaum et al., 1978), ether inhalation (Aguila et al., 1991), immobilization (Benyassi et al., 1993) and cold exposure (Arancibia et al., 1987; Arancibia et al., 1995). All of these responses are likely mediated by fast neurotransmitters which likely modify storage pools that will need to be subsequently restored in order to be ready for new physiological requirements. In fact, very early we showed a significant increase in somatostatin release in the median eminence after acute immobilization (IMO) stress stimulus as compared to unstressed animals. This peak of somatostatin release seems to trigger a decrease in plasma $\mathrm{GH}$, one of the hormonal variations observed after stress application in rats, and that we measured in the same animals (Benyassi et al., 1993). However, when animals have been previously injected (30 min before) with MK-801, an antagonist of NMDA-type glutamate receptors, the peak of somatostatin secretion observed after stress application is completely abolished, thus showing glutamatergic control tonus in this regulation.

The equilibrium between neurotransmitters (such as catecholamines, serotonin or glutamate), systemic hormones (such as glucocorticoids) and free radicals formed at the tissular level, will determine the adaptation or, on the contrary, the deleterious effects attributed to stress. In this subtle equilibrium, protective molecules are certainly involved in adaptation, which is the most common response to stress. In this context, we postulated that neurotrophins could be involved in the stress response to protect neurons against some harmful effects of stress. It is well documented that stress represents an important modulating stimulus on plasticity processes. LTP, an electrophysiological model of learning 
and memory linked to plasticity processes, can thus be deeply altered by previous stress application (Shors \& Dryver, 1994). In fact, stress may induce changes in thresholds for synaptic plasticity necessary for LTP (Garcia, 2001).

In this review, we discuss a body of evidence indicating that neuronal plasticity represents a morphofunctional substrate that could be strongly affected by the female sexual status, i.e., by cyclical influences of ovarian hormones. A stress stimulus will thus generate a response dependent on the underlying sexual status. A second goal of this review is to present some experimental data supporting the hypothesis that BDNF plays a role in the plasticity process triggered by the stress stimulus, and finally, to underline the importance of the hypothalamic median eminence (ME) as a locus where plasticity processes occur to ensure neurohormonal release. Our examples refer to somatostatin, a pleiotropic neurohormone that we have extensively studied in our laboratory and whose pertinence in the present framework is warranted due to its involvement in the stress response as well as its regulation by sexual steroids and BDNF.

\section{Stress and Ovarian Hormone Interactions}

Since GC receptors have been identified in somatostatin neurons of the $\mathrm{PeV}$ nucleus that project to the ME, we investigated whether they were involved in the control of somatostatin neurons. A single dose of dexamethasone (Dex), a synthetic glucocorticoid i.p. administered to free-moving adult male rats (injection of $100 \mathrm{mg} / 100 \mathrm{~g}$ ), induced, within 15-30 min, a peak of somatostatin secretion from the median eminence collected by push-pull perfusion (Estupina et al., 1997). This quick effect of GC could represent a rapid and direct control mechanism on these neurons. An indirect $\mathrm{CRH}$-mediated effect might also be possible since GC control CRH release, and considering the anatomical connections that exist between $\mathrm{CRH}$ and somatostatin neurons.

Experiments were carried out to determine the effects of acute IMO stress or Dex administration on somatostatin synthesis in the PeV nucleus of male rats. Measurements of cells expressing somatostatin mRNA in discrete hypothalamic regions were analyzed by in situ hybridization (ISH), total hypothalamic somatostatin mRNA was determined by Northern blot and somatostatin content was measured by RIA. We documented that IMO stress strongly reduces the number of cells expressing somatostatin mRNA (Arancibia et al., 2000 ). This number of cells parameter, was chosen because DIG-labeled probes facilitate, better than radioactive probes, clear detection and cell counting due to the high resolution power. The inhibitory effect was also obtained when we analyzed mRNA levels by Northern blot in total hypothalamus. The total peptide content followed the same profile as total mRNA. The very rapid inhibitory effect of stress on neurons expressing somatostatin mRNA was reproduced by administration of Dex. However, surprisingly, a significant increase in somatostatin mRNA levels was observed when experiments were carried out using a more sensitive radioactive ISH. This suggests that a subset of periventricular neurons synthetizing somatostatin is regulated 
independently, which is an interesting example of neuronal plasticity. In this example, a subset of somatostatinergic cells became silent when neighbourgh cells were maximally reactive. The increase in somatostatin mRNA, as estimated by radioactive ISH, could help to explain the peak of somatostatin release precociously induced by stress application (Benyassi et al., 1993). In contrast, the decrease in the number of cells expressing the messenger detected with DIG-labeled probe could be a consequence of somatostatin ultrashort feed-back mechanisms (Epelbaum et al., 1986) through autoreceptors located on the PeV nucleus itself (Helboe et al., 1998), which would be activated by the stress stimulus.

In addition to the stress influence, we have demonstrated that in female rats, hypothalamic somatostatin content and release are sensitive to physiological fluctuations in ovarian steroids (Estupina et al., 1996 $6^{\mathrm{b}}$ ). The secretory pattern of somatostatin release in free-moving female rats exhibits steroid-independent peaks, contrary to that observed with basal release, which seems to depend on gonadal influences. Both somatostatin content and release were significantly decreased during the estrous stage as compared to values measured in proestrus which coincides with the decrease in somatostatin synthesis reported by others (Zorilla et al., 1990; Zorilla et al., 1991). This model illustrates a subtle double control exerted by sexual steroids on this neurohormonal secretion and it could underlie physiological basis for plasticity modifications since steroid control generally seems important in plasticity processes.. In fact, in addition to stress, the hormonal ovarian status is another key factor underlying changes in cellular plasticity, or perhaps metaplasticity. Furthermore, the two influences seem to act interdependent. Indeed, the experiments reported by Kelly et al. (1977) revealed that the sensitivity of membrane responses evoked by iontophoretic application of some steroids depends on the estrous cycle. Inasmuch as the neuronal plasticity concept was not yet common in neurobiology, the importance of these data was not sufficiently tapped. Presently, the sexual status should be considered to operate as a membrane priming effect, which subsequently determines the response to new stimuli.

Thus, since the secretory process of somatostatin is normally dependent on sexual steroids and also sensitive to stress stimuli, an ex vivo model of incubated hypothalamic fragments was considered an adequate protocol to study these interactions. In the recent past, we have shown that tissues dissected from stressed animals react in vitro to chemical depolarization in a sexual status-dependent manner (Arancibia et al., 1997). Ten-min incubations of hypothalamic fragments in Locke's medium containing 40 $\mathrm{mM} \mathrm{K} \mathrm{K}^{+}$did not induce a significant increase in somatostatin release above basal levels, irrespective of the estrous cycle stage of the donor rats. However, tissues dissected from either 10-day ovariectomized rats or 17-day pregnant rats markedly and significantly responded to $\mathrm{K}^{+}$. In contrast, when donor animals were previously stressed by 30-min cold exposure at $4^{\circ} \mathrm{C}$, a significantly increased response to $\mathrm{K}^{+}$was observed throughout estrous cycle, with the exception of the diestrus-1 (D-I) stage. In the stressed groups, it 
was found that basal somatostatin release was lower than in control animals, except in estrus and diestrus-2 (D-II) stages. These data strongly suggested that endogenous neurotransmitters, rapidly released during stressor application, could modify spontaneous release of somatostatin. GABA was found to be a good candidate for two main reasons: firstly, because the GABA-A receptor linked to a Cl-channel is involved in the inhibitory control of somatostatin release (Gamse et al., 1980; Arancibia \& Briozzo, 1990; Rage et al., 1992) and synthesis (Rage et al., 1993); secondly, the release of this neurotransmitter is rapidly activated under cold exposure (Arancibia et al., 1995), and GABA levels in the synaptic cleft are increased by cold exposure (Acosta et al., 1993). Moreover, the involvement of GABA is in accordance with the fact that different acute stressors can diminish (Biggio et al., 1987) or potentiate (Schwartz et al., 1987) the GABA-A receptor function. Cortical slices from stressed animals have been shown to display higher levels of spontaneous GABA release than slices from habituated animals (File et al., 1990). Besides, sustained modification of GABA-A receptors could be induced by neuroactive steroids whose concentrations in the brain were reported to be enhanced after stress application (Paul \& Purdy, 1992). The term "neuroactive steroids" includes all steroids which are active on neuronal tissue, whether they are synthetized in the brain or not. Therefore, these steroids could be of different origin, i.e. peripheral or nervous (neurosteroids).

Apart the classical genomic actions of steroids, these molecules may rapidly alter neuron excitability through membrane actions (McEwen, 1991), so the results observed in tissues dissected from stressed females could be explained by a prior priming genomic effect of neuroactive steroids released during stress. It has been reported that after intracellular oxidation into $5 \alpha$-pregnan steroids the neurosteroids activate the progesterone receptor at the DNA level (Rupprecht et al., 1993). It is known that some genomic effects of steroids can be very rapid (Mosher et al., 1971), i.e. less than the 30min of cold exposure applied in our experiments.

Further evidence in favour of steroid involvement in the GABA/somatostatin interaction was obtained in in vitro experiments using a steroid-free media in primary cultures. Neither GABA (100 mM) nor bicuculline $(100 \mathrm{mM})$ influenced basal somastostatin release. However, when steroids were precociously present in the culture media (D1-D4), the inhibitory effect of GABA on somatostatin release was clearly observed. Interestingly, basal somatostatin release increased significantly as compared to that released when steroids were suppressed in the media. In line with in vitro data on fetal neurons, when we used incubated adult tissue, whatever the stage of the sexual cycle (proestrus or diestrus) of donor female rats, neither GABA (100 mM for $15 \mathrm{~min}$ ) nor picrotoxine (100 mM for 15 min) were able to modify basal somatostatin release. However, in vivo data showed contrary results since i.p. administration of bicuculline to female rats induced, in estrus but not in diestrus, a clear modification in the previously established in vivo secretory pattern of somatostatin (Estupina et al., 1996 $6^{\mathrm{b}}$ ). Using the push-pull perfusion technique (Ramirez, 1985; Arancibia, 1987), we showed that somatostatin secretion was tonically inhibited by 
GABA, in a steroid-dependent fashion, since bicuculline injections modified the total amount of somatostatin secreted in estrus but not in diestrus and in ovariectomized rats, whereas the GABA-A antagonist had no effect on total somatostatin secretion (Arancibia et al., 1997). Besides, the well known in vivo inhibitory effect of GABA on somatostatin release (Arancibia \& Briozzo, 1990), which is also documented in primary cultures of fetal hypothalamic neurons (Rage et al., 1992), was not observed in in vitro incubations. Actually, unless the neurosteroid THDOC $\left(10^{-5} \mathrm{M}\right)$ is jointly added to the incubation media, the GABA inhibitory effect could no longer be observed.

Thus, it appears that the GABA-A receptor is an important "crossroad" in stress pathways, interacting with ovarian steroid and neurosteroid responses. We have proposed that all of these signals converge to modulate neuronal plasticity process. In fact, both ovarian steroids (Earley \& Leonard, 1980; Wilson \& Biscardi, 1994) and stress (Biggio \& Concas, 1984; Purdy et al., 1991; Akinci \& Johnston, 1997) are able to modify the number and affinity of GABA-A receptors in several regions of the CNS. The GABAA receptor is also a major target of neurosteroids (Robel \& Baulieu, 1994) whose concentrations fluctuate in the brain as a function of the ovulatory cycle (Karavolas \& Hodges, 1990) and stress (Paul \& Purdy, 1992; Korneyev et al., 1993). Furthermore, the binding potency of neurosteroids on the GABA-A receptor is dependent on ovarian cycle influences (Finn \& Gee, 1993).

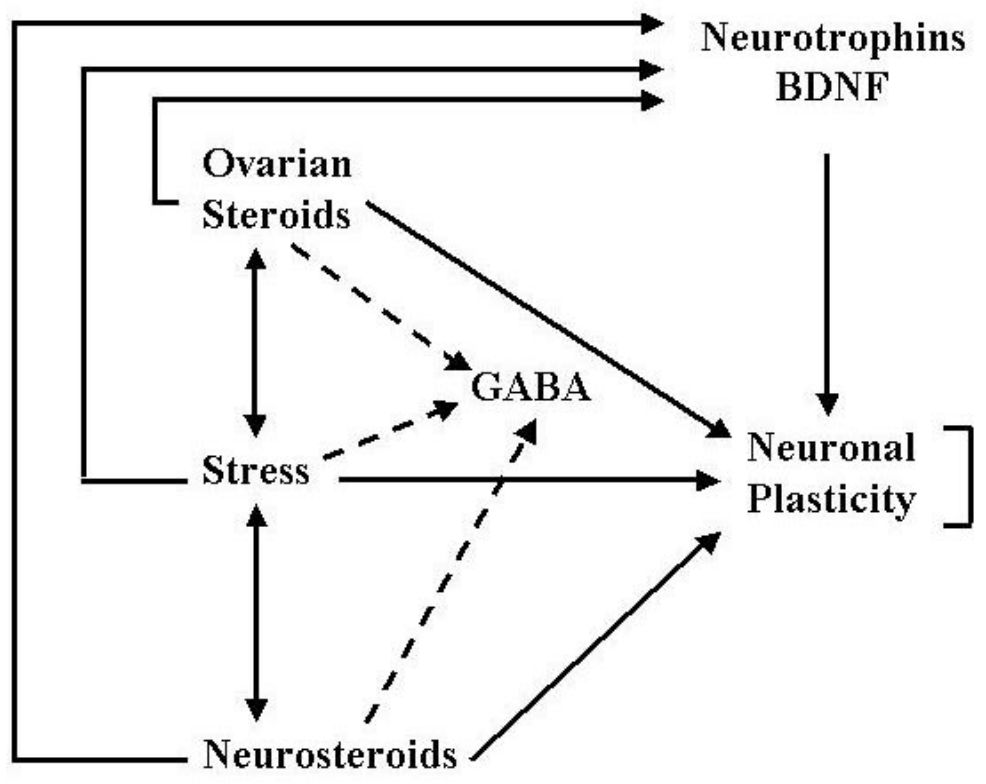

\section{Conclusion}

Taken as a whole these data indicate a close interaction between stress, ovarian steroids and neurosteroids in neuronal plasticity, and these effects probably linked through GABA-A receptor modulation (see figure just above). The high plasticity of hypothalamic tissue illustrated by these interactions (ovarian steroids, neurosteroids and stress) led us 
to study neurotrophins, particularly BDNF, as plasticity related molecules. It is important to note that in some brain regions BDNF mRNA levels are affected by physiological changes in circulating gonadal steroids levels, and that gonadectomy induces an increase in BDNF protein levels (Solum \& Handa, 2002). Furthermore, an estrogen response element was found to be present in the BDNF gene (Sohrabji et al., 1995) in addition to the colocalization of estrogen receptors with $\operatorname{TrkB}$ receptors in the adult basal forebrain (Toran-Allerand et al., 1992). Moreover, in the hippocampus, BDNF mRNA levels have been reported to fluctuate across the estrous cycle and to be sensitive to acute hormone replacement (Gibbs, 1998). These findings are in keeping with the role of ovarian steroids in the control of neuronal connectivity in the female hippocampus (Desmond \& Levy, 1997) and with the neuroprotective effects of estrogens (Green \& Simpkins, 2000) and neurosteroids (Dubrovsky, 2000) through the central nervous system.

\section{BDNF, a Neurotrophin Involved in the Stress Response}

We demonstrated that immobilization stress induced rapid upregulation of BDNF mRNA in the hypothalamus, measured by RNAse protection assay, and this was already significant $15 \mathrm{~min}$ following stress onset. This rise was followed by an increase in BDNF peptide measured by ELISA (Rage et al., 2002). The analysis of variations in individual BDNF mRNA transcript levels by RT-PCR showed that the early increase in BDNF mRNA expression resulted from increased expression of transcripts containing exon III, which was increased at $15 \mathrm{~min}$. In contrast, belated changes have been the result of modifications in exon I expression, which remained elevated for longer times. In contrast, mRNAs containing exons II and IV were not significantly changed after different times of stress application, except after 5 h-stress, when transcripts containing exon IV decreased significantly.

ISH studies allowed us to detect BDNF mRNA in discrete regions involved in the stress response. Thus, we detected high levels of mRNA: 1) in the PaVN, a site where the main stress hormones, $\mathrm{CRH}$ and AVP, are synthetized; 2) in the PeVN where somatostatin is synthetized (as stated above, somatostatin is an inhibitory neurohormone modified in all stress situations studied so far); 3) in the SON, where vasopressin and oxytocin are synthetized, two hormones released after osmotic stimuli. Finally, we detected BDNF mRNA 4) in the median eminence, the compartment of hormone release; and 5) in the pituitary (Givalois et al., 2001), which is an essential link between the CNS and the peripheral adrenal response.

In basal or stress conditions, the BDNF hybridization signal was not homogenous in the PVN, whereas the signal distribution was fairly homogenous in the SON. These signals were strongly increased after IMO stress stimulus applied for different times. They were quantified while taking into account the three subdivisions of the PVN: medial parvocellular PVN, lateral magnocellular PVN and ventral PVN. The three PVN 
subdivisions correspond to three functionally different subgroups of neurons. To address the question concerning the physiological significance of these BDNF mRNA modifications, we examined the expression patterns of AVP, BDNF and CRH mRNAs by in situ hybridization on adjacent sections of the PVN after different immobilization stress times. We observed that in the parvocellular or magnocellular region of the PVN, BDNF signal augmentation preceded $\mathrm{CRH}$ and vasopressin mRNA signal increases, respectively. In the magnocellular portion of the PVN, where vasopressin and oxytocin neurons are essentially found, an increased signal was observed after 60 min of stress, whereas in the parvocellular division, where $\mathrm{CRH}$ neurons are essentially localized, the signal showed early variations, i.e. within 15 min. In the SON, BDNF mRNA expression increased significantly after 60 min of IMO stress, and the signal was homogenously distributed throughout the nucleus.

In the $\mathrm{SON}$, we also showed that after IMO stress a BDNF signal increase preceded the increase in the vasopressin signal. This effect seems to be due to a transcription rate augmentation since the number of positive cells per section was not modified but the number of silver grains per cell was increased. The peptide increase is belated as compared with mRNA time-courses, which is coherent considering the time necessary for the translation process. In any case, the augmentation of the peptide, which ultimately represents the active molecule, is very rapid after the onset of stress in all hypothalamic regions studied, thus indicating BDNF involvement in the stress response. A more specific stress for SON, such as osmotic stress (Luo et al., 1994), was also studied. A significant increase in BDNF mRNA levels was observed in the SON $3 \mathrm{~h}$ after application of the osmotic stimulus (Aliaga et al., 2002). Furthermore, our data suggested that this change resulted from increased expression of transcripts containing exon I. In contrast, transcripts containing exon II or III were not significantly changed. Acute intraperitoneal injection of hypertonic saline used in this study is known to induce cellular dehydration (Watts, 1996) and represents a powerful and specific stimulus for rapid AVP release, as measured by its increased plasma levels within 30 min (Neumann et al., 1993). The fact that BDNF mRNA in the SON is sensitive to the osmotic stimulus suggests a physiological role for this neurotrophin in the AVP secretory process. Actually, a paracrine or autocrine action is a generally recognized mechanism for neurotrophin action in the CNS (Kokaia et al., 1993). We showed, using $12 \mathrm{~mm}$-histological serial sections of SON, that cells synthetizing BDNF are close to or even whithin the same cell as those synthesizing the neurohormone. These data favor a paracrine or autocrine role of BDNF on AVP secretion. Using the push-pull perfusion technique, we measured BDNF release from SON in free-moving rats subjected to osmotic stress (Arancibia et al., unpublished results). A pulsatile profile of BDNF secretion with peaks occurring $4 \mathrm{~h}$ after stress was observed. The peak of BDNF secretion could be correlated with the AVP synthesis process which occurs $6 \mathrm{~h}$ after osmotic stress application (Marmigère et al., 1998). Apart from a possible action on AVP synthesis, an early variation in BDNF could affect in fine the strength of synaptic connections or dendritic spine density. A presynaptic locus of action of BDNF to increase synaptic vesicle density, 
which is critical for rapid synaptic transmission, has been reported during development (Colin, 2001). In addition, BDNF enhances neurotransmitter release at the presynaptic level by phosphorylation of synapsins I and II (Jovanovic et al., 1996; Jovanovic et al., 2000).

As for the PeV nucleus, we observed a reduction in BDNF mRNA levels after stress IMO exposure. This effect was prevented by prior injection of MK-801, similar to the pattern observed with this drug when it blocked stress-induced somatostatin release (Estupina et al., 1996 ${ }^{\mathrm{a}}$. Although we do not yet have formal evidence of the cellular colocalization of BDNF and somatostatin, ISH studies clearly revealed that BDNF is synthesized in the PeV nucleus, the main hypothalamic source of somatostatin. BDNF is likely involved as a mediator in the stress-induced somatostatin response. In vitro, we have shown in hypothalamic neurons that BDNF is able to strongly stimulate somatostatin synthesis (mRNA and peptide) in a dose-dependent manner. Using immunocytochemical studies combined with quantitative analysis, we determined that the neurotrophin stimulated somatostatin turnover and that this was not simply a nonspecific effect on neuron survival. In addition, we have shown, with double immunocytochemical staining, that somatostatin neurons possess BDNF receptors, i.e. TrkB (Rage et al., 1999). These data provide morphological and functional evidence indicating a direct effect of BDNF on somatostatin neurons in vivo.

Finally, single icv injections of BDNF increase $\mathrm{CRH}$ hypothalamic content at $48 \mathrm{~h}$, with a decrease at the earliest times, suggesting a stimulatory effect of BDNF on $\mathrm{CRH}$ release since it is correlated with ACTH plasma levels measured in these animals (Givalois et al., unpublished results). In addition, acute icv microinjections of BDNF are able to decrease somatostatin content in the hypothalamus, accompanied by a decrease in plasma GH, suggesting that an increase in somatostatin release might occur after BDNF injection. This effect clearly mimicks the stimulatory effect of stress on somatostatin release (Benyassi et al., 1993). In contrast, since stress induces a BDNF mRNA decrease in the PeV nucleus (Arancibia et al., 2000 ) and given that BDNF seems to stimulate somatostatin synthesis (Rage et al., 1999), a decrease in BDNF due to a stress stimulus could result in a decrease in somatostatin mRNA, as observed in ISH experiments following stress (Arancibia et al., 2000 ). If this decrease in the messenger results in diminished release, this effect might arise from activation of ultra-short feedback, which might be involved in the somatostatin regulation (Epelbaum et al., 1986).

\section{Conclusion}

This section summarizes results that indicate major involvement of BDNF in the hypothalamic plasticity phenomena measured on the basis of modifications in BDNF mRNA and protein levels in different hypothalamic nuclei following stress stimulus application. Since we have shown that BDNF is a potent stimulatory agent of peptide synthesis and that the BDNF mRNA increase precedes vasopressin and CRH mRNA 
increases, we hypothesize that BDNF could help to replenish intracellular peptidergic stores after rapid and massive hormone release induced by a stress stimulus. This replenishment of secretory stores could serve as a protective mechanism against harmful effects of stress on neurons. This hypothesis is confirmed by very recent results, showing that a single BDNF administration increases CRH and AVP hypothalamic content, with alterations in the release of their respective pituitary hormones. Likewise, somatostatin, considered to be a major modulator of $\mathrm{CRH}$ secretion (see Introduction), exhibits important modifications after icv BDNF administration.

\section{Plasticity and Neurohormonal Release}

The median eminence (ME) is a neurohemal structure considered to be the final common pathway connecting the nervous and endocrine systems. The most studied process of neurohormone release at the ME level corresponds to GnRH release, whose mechanisms involving plasticity phenomena have already been discussed in review articles on this topic (Melcangi et al., 2002; Prevot, 2002). GnRH was the first neurohormone measured in vivo by push-pull perfusion (Levine \& Ramirez, 1980). As occurs for stress reactions, somatostatin is also linked to the reproduction function and GnRH control since somatostatin is the major inhibitory neurohormone controlling GH secretion. This latter hormone participates in the production of signals conveyed to the brain for GnRH neuron activation. Growth molecules, such as IGF-I, leptine, insulin are all important signals for a pubertal increase in gonadotropin secretion (Bucholtz et al., 1996). To ensure both normal growth and reproductive capacities, the nutritional state is a very important parameter which is obviously linked to control of the appetite (Recabarren et al., 2002). In line with this, a non-neurotrophic action of BDNF was recently reported, involving a loss of body weight (Pelleymounter et al., 1995), likely due to a decrease in food intake (Kernie et al., 2000). Moreover, deletion of the BDNF gene provokes obesity and hyperactivity (Rios et al., 2001). Although these different experiments did not reveal the locus of BDNF action, it is likely that the hypothalamus is involved in this novel action of the neurotrophin that links metabolic and reproductive functions.

In general, important changes in morphological plasticity occur at the ME level to ensure the appropriate physical contact between nerve endings and parenchymatous basal lamina, which should facilitate subsequent neurohormone entry into the portal vessels. Actually, neurohormone release at ME nerve endings results from dynamic interactions of cell-to-cell communication processes involving several cellular elements such as glial (astrocytes), glial-like (tanycytes) and endothelial cells (Prevot, 2002; Dhandapani et al., 2003), as well as laminin and fibronectin fibrils of the extracellular matrix (King \& Letourneau, 1994). Given the recognized role of BDNF in plasticity processes, we investigated whether or not BDNF could be present in some or all of the cellular components mentioned above as involved in the neurohormone release at the ME level. 
After application of immunohistochemical procedures, the ME was explored by photonic and electronic microscopy to detect the potential presence of BDNF mRNA, the protein and the receptor $\operatorname{TrkB}$ in this tissue. Double staining with specific cellular markers (vimentine, GFAP, synaptophysin) associated with an antibody against BDNF allowed us to visualize, by fluorescence microscopy, the different cellular elements involved in these complex interactions (Givalois et al., unpublished data).

\section{BDNF in Astrocytes}

BDNF accumulation was strongly detected in the inner layer of ME, close to the floor of the third ventricle. This localization might correspond to tanycyte bodies or to astrocyte processes. Tanycytes belong to specialized glial cells exhibiting an elongated shape, with one cytoplasmic end that contacts the surface of the third ventricle and with other end contacting neurosecretory terminals in the external layer of the ME. Astrocytes are glial cells present in the ME whose processes, unlike those of tanycytes, stretch parallel to the ventricular surface (Kawakami, 2000). More accurate studies using double immunocytochemical staining revealed that astrocytes are an important source of BDNF in the internal ME, since GFAP, a specific marker of glial cells, strongly stains these cells, which were also stained with the BDNF antibody. According to their classical role, astrocytes seem to regulate neuronal metabolism and activity. This property may be achieved by regulating glucose supply, extracellular ion concentrations, cerebral blood flow and neurotransmitter levels, as well as by releasing neuroactive substances and trophic factors (Garcia-Segura et al., 1996). The TrkB receptor was localized essentially on tanycytes but also in astrocytes and nerve endings. These data suggest that BDNF could stimulate the metabolic activity of astrocytes through an autocrine or paracrine action already reported for neurotrophins (Kokaia et al., 193). In this case, BDNF could also favor the release from astrocytes of factors that could affect the neurosecretory activity in targets cells. In fact, it is known that hypothalamic glial cells are able to accumulate several growth factors (Fernandez-Galaz et al., 1996) and that they are sources of other trophic factors, such as NGF (Pioro \& Cuello, 1990) TGFa (Ma et al., 1992) or IGF-I (Dueñas et al., 1994).

\section{BDNF in Tanycytes and Nerve Endings}

Using double immunocytochemical staining, $\operatorname{TrkB}$ receptors were observed in vimentine stained regions close to tanycyte feet, but also along tanycytal processes as well as in tanycyte bodies. BDNF could thus be released from astrocytes to act on tanycytes and even on ME nerve endings, since the synaptophysin marker was colocalized with TrkB at this level. Growth factors, other than BDNF, such as TGFa and IGF-I are released from astrocytes to control GnRH release (Ojeda et al., 1992). A biological action of BDNF on axonal terminals might correspond to presynaptic action of neurotrophins. This possibility is compatible with reported BDNF effects that facilitate neurotransmitter release 
through MAP kinase-induced synapsin I activation (Javanovic et al., 1996). Phosphorylation of synapsins I and II are presynaptic effectors for the acute action of BDNF at the synapse (Javanovic et al., 2000). Note that nerve endings in the external ME layer can be considered as presynaptic terminals, with the postsynaptic-like element being the pituitary (Arancibia \& Tapia-Arancibia, 1989). Terminals represent a locus of action of neurotrophins to increase, for example, synaptic vesicle density, a critical event for rapid synaptic transmission (Collin et al., 2001). Recent data on the presence of the somatostatin receptor on tanycyte cells (Hashemi et al., 2001) lead us to envisage a new role for this neurohormone in secretory processes, likely in interactions with BDNF, to mediate endocrine releasing processes related to stress and/or reproductive physiology. Interactions between growth factors and steroid hormones seem to occur in the perivascular space. During proestrus, GnRH nerve endings make physical contact with basal lamina, whereas in diestrus II these contacts disappear (Prevot et al., 1999).

Furthermore, the presence of $\operatorname{TrkB}$ receptors on tanycytes might explain the sprouting and retracting capacities of these cells, since similar actions are recognized for BDNF in neuronal sprouting phenomena at different levels in the CNS (Smith et al., 1997; Scharfman et al., 1999). Interestingly, in the ME, regenerative axon sprouting always occurs in close association with tanycyte processes (Chauvet et al., 1998). Moreover, since immunoreactive BDNF has been revealed in tanycytes, although weakly, this could explain why these cells, when transplanted in the spinal cord, significantly support the regeneration of lesioned axons (Prieto et al., 2000).

\section{Stress Stimulus}

Since stress represents a physiological situation that is able to activate plasticity processes, we delivered IMO stress to rats at different times and examined morphological and functional changes in the ME. These data are of considerable interest since glucocorticoids increase in plasma after stress and tanycytes undergo cellular alterations after adrenalectomy (Brion et al., 1982). Immunocytochemical studies show that the BDNF protein is also sensitive to the IMO stress stimulus. Interestingly, after stress application, TrkB staining is strongly increased in regions where the stain is colocalized with specific markers for the cellular elements analysed above, i.e. tanycytes, astrocytes and nerve ending elements.

A significant increase in BDNF mRNA was evident as early as 15 min after stress application in the internal ME region, a phenomenon that is followed by the accumulation of BDNF peptide at 30 and 60 min of stress, as revealed by immunohistochemical procedures. The rapid appearance of a significant increase in BDNF mRNA levels is not very surprising since we recently reported that BDNF mRNA levels in different hypothalamic nuclei are extremely and rapidly sensitive to stress stimuli (Rage et al., 1992). Likewise, we observed a rapid increase in BDNF protein levels in different hypothalamic nuclei since mRNA seems to be rapidly translated into protein following 
stress stimuli (Rage et al., 1992). The increase in immunoreactive BDNF staining is observed at 30 and $60 \mathrm{~min}$ in the inner ME layer, whereas immunoreactive BDNF in the outer ME layer appears later, i.e. at $180 \mathrm{~min}$, when the signal in the inner layer has returned to basal values. A peak of BDNF release is observed at 30-45 min after stress onset monitored in unanesthetized free-moving rats by using the push-pull perfusion technique. In all of these experiments, corticosterone plasma levels were measured in stressed animals and they exhibited a pattern compatible with the classical hormonal reaction to stress.

\section{Conclusion}

Our results show the presence of BDNF mRNA, BDNF peptide and BDNF receptor in the $\mathrm{ME}$ as well as BDNF release from this neuroendocrine structure. In addition, these molecules are affected by stress stimulus. BDNF synthetized in astrocytes is a novel finding, and its action might concern neurohormone release because its specific receptor, $\operatorname{TrkB}$, is mainly located on tanycytes but also on the astrocytes and nerve endings.

BDNF might be an important signal involved in morphological plasticity changes which facilitate neurohormone secretory events. In fact, BDNF receptors located in tanycytes and nerve endings in the outer layer of the ME, favors a BDNF role in the hypothalamic secretory process. This is an important clue because so far BDNF has only been associated with the neurohormone synthesizing process and not with their release.

\section{Acknowledgements}

We thank Mr. E. Savary for technical help.

\section{References}

Abraham WC, Tate WP. Metaplasticity: A new vista across the field of synaptic plasticity. Prog Neurobiol 1997;52:303-23.

Acosta GB, Otero-Losada ME, Rubio MC. Area-dependent changes in GABAergic function after acute and chronic cold stress. Neurosci Lett 1993;154:175-8.

Aguila MC, Pickle RL, Yu WH, McCann SM. Roles of somatostatin and growth hormonereleasing factor in ether stress inhibition of growth hormone release. Neuroendocrinology 1991;54:515-20.

Akinci MK, Johnston GA. Sex differences in the effects of gonadectomy and acute swim stress on $\mathrm{GABA}_{\mathrm{A}}$ receptor binding in mouse forebrain membranes. Neurochem Int 1997;31:1-10.

Aliaga E, Arancibia S, Givalois L, Tapia-Arancibia L. Osmotic stress increases brainderived neurotrophic factor messenger RNA expression in the hypothalamic supraoptic nucleus with differential regulation of its transcripts. Relation to arginin-vasopressin content. Neuroscience 2002;112:841-50. 
Arancibia S. La technique de perfusion «push-pull» en Neuroendocrinologie. Ann Endocrinol (Paris) 1987;48:410-8.

Arancibia S, Briozzo P. Peripheral administration of picrotoxin and bicuculline stimulates in vivo somatostatin release from rat median eminence. Neurosci Lett 1990;111:211-6.

Arancibia S, Estupina C, Pesco J, Belmar J, Tapia-Arancibia L. Responsiveness to depolarization of hypothalamic neurons secreting somatostatin under stress and estrous cycle conditions. Involvement of GABAergic and steroidal interactions. J Neurosci Res 1997;50:575-84.

Arancibia S, Estupina C, Tapia-Arancibia L. Rapid reduction in somatostatin mRNA expression by hypothalamic neurons induced by dexamethasone. NeuroReport $2000^{\mathrm{a}} ; 11: 3163-7$.

Arancibia S, Lyonnet D, Roussel JP, Ixart G, Astier H. The inhibitory effect of picrotoxin on basal and cold-induced TSH secretion involves somatostatin mediation. Neurosci Lett 1995;185:139-43.

Arancibia S, Rage F, Grauges P, Gomez F, Tapia-Arancibia L, Armario A. Rapid modifications of somatostatin neuron activity in the periventricular nucleus after acute stress. Exp Brain Res 2000 $; 134: 261-7$.

Arancibia S, Tapia-Arancibia L, Assenmacher I. Effect of acute exposure to cold on SRIF release in unanesthetized rats and its temporal correlationship with the cold induced TRH peak. Exp Clin Endocrinol (Life Sci Adv) 1987;6:265-8.

Arancibia S, Tapia-Arancibia L. Nerve ending receptors in the median eminence. Pharmacological and physiological data on TRH and SRIF secreting neurons. Exp Clin Endocrinol (Life Sci Adv) 1989;8:51-61.

Arimura A, Smith WD, Schally AV. Blockade of the stress-induced decrease in blood GH by anti-somatostatin serum in rats. Endocrinology 1976;98:540-3.

Baxter GT, Radeke MJ, Kuo RC, Makrides V, Hinkle B, Hoang R, et al. Signal transduction mediated by the truncated trkB receptor isoforms, trkB.T1 and trkB.T2. J Neurosci 1997;17:2683-90.

Benyassi A, Gavaldà A, Armario A, Arancibia S. Role of somatostatin in the acute immobilization stress-induced GH decrease in rat. Life Sci 1993;52:361-70.

Bhatnagar M. Acute and transient effects of stress on immunoreactive somatostatin cell bodies and fibers in the preoptic-anterior hypothalamus and median eminence of female rats. J Biosci 1999;24:171-6.

Biggio G, Concas A, Mele S, Corda MG. Changes in GABAergic transmission induced by stress, anxiogenic and anxiolytic $\beta$-carbolines. Brain Res Bull 1987;19:301-8.

Biggio G, Concas A, Serra M, Salis M, Corda MG, Murchi V, et al. Stress and b-carbolines decrease the density of low affinity GABA binding sites: an effect reversed by diazepan. Brain Res 1984;305:13-18.

Brazeau P, Vale W, Burgus R, Ling N, Butcher M, Rivier J, et al. Hypothalamic polypeptide that inhibits the secretion of immunoreactive pituitary growth hormone. Science 
1973;179:77-9.

Brion JP, Depierreux M, Couck AM, Flament-Durand J. Transmission and scanning electronmicroscopic observations on tanycytes in the mediobasal hypothalamus and the median eminence of adrenalectomized rats. Cell Tissue Res 1982;221:643-55.

Brown MR, Rivier C, Vale W. Central nervous system regulation of adrenocorticotropin secretion: role of somatostatins. Endocrinology 1984;114:1546-9.

Castren E, Thoenen H, Lindholm D. Brain-derived neurotrophic factor messenger RNA is expressed in the septum, hypothalamus and in adrenergic brain stem nuclei of adult rat brain and is increased by osmotic stimulation in the paraventricular nucleus. Neuroscience 1995;64:71-80.

Chauvet N, Prieto M, Alonso G. Tanycytes present in the adult rat mediobasal hypothalamus support the regeneration of monoaminergic axons. Exp Neurol 1998;151:1-13.

Chew SL. Alternative splicing of mRNA as a mode of endocrine regulation. Trends Endocrinol Metab 1997;8:405-13.

Collin C, Vicario-Abejon C, Rubio ME, Wenthold RJ, McKay RDG, Segal M. Neurotrophins act at presynaptic terminals to activate synapses among cultured hippocampal neurons. Eur J Neurosci 2001;13:1273-82.

Conner JM, Lauterborn JC, Yan Q, Gall CM, Varon S. Distribution of brain-derived neurotrophic factor $(\mathrm{BDNF})$ protein and $\mathrm{mRNA}$ in the normal adult rat CNS: evidence for anterograde axonal transport. J Neurosci 1997;17:2295-313.

Desmond NL, Levy WB. Ovarian steroidal control of connectivity in the female hippocampus: an overview of recent experimental findings and speculations on its functional consequences. Hippocampus 1997;7:239-45.

Dhandapani KM, Mahesh VB, Brann DW. Astrocytes and brain function: implications for reproduction. Exp Biol Med 2003;228:253-60.

Dobson H, Ghuman S, Prabhakar S, Smith R. A conceptual model of the influence of stress on female reproduction. Reproduction 2003;125:151-63.

Dubrovsky B. The specificity of stress responses to different nocuous stimuli: Neurosteroids and depression. Brain Res Bull 2000;51:443-55.

Dueñas M, Luquin S, Chowen JA, Torres-Aleran I, Naftolin F, Garcia-Segura LM. Gonadal hormone regulation of insulin-like growth factor-I-like immunoreactivity in hypothalamic astroglia of developing and adult rats. Neuroendocrinology 1994;59:528-38.

Earley CF, Leonard BE. GABA and gonadal hormones. Brain Res 1980;27-34.

Enjalbert A, Epelbaum J, Arancibia S, Tapia-Arancibia L, Bluet-Pajot MT, Kordon C. Reciprocal interactions of somatostatin with thyrotropin-releasing hormone and vasoactive intestinal peptide on prolactine and growth hormone in vitro. Endocrinology 1982;111:42-7.

Epelbaum J, Tapia-Arancibia L, Alonso G, Astier H, Kordon C. The anterior periventricular hypothalamus is the site of somatostatin inhibition on its own release: an in vitro and 
immunocytochemical study. Neuroendocrinology 1986;44:255-9.

Estupina C, Abarca J, Arancibia S, Belmar J. N-Methyl-D-aspartate receptor involvement in the dexamethasone and stress-induced hypothalamic somatostatin release in rats. Neurosci Lett 1996; $219: 203-6$.

Estupina C, Belmar J, Tapia-Arancibia L, Astier H, Arancibia S. Rapid and opposite effects of dexamethasone on in vivo and in vitro hypothalamic somatostatin release. Exp Brain Res 1997;113:337-42.

Estupina C, Pinter A, Belmar J, Astier H, Arancibia S. Variations in hypothalamic somatostatin release and content during the estrous cycle in rats. Effects of ovariectomy and estrogen supplementation. Neuroendocrinology 1996 ; 63:181-7.

Fernandez-Galaz MC, Torres-Aleman I, Garcia-Segura LM. Endocrine-dependent accumulation of IGF-I by hypothalamic glia. NeuroReport 1996;8:373-7.

File SE, Andrews N, Zharkovsky A. Handling habituation and chlordiazepoxide have different effects on GABA and 5-HT function in the frontal cortex and hippocampus. Eur J Pharmacol 1990;190:229-34.

Finn DA, Gee KW. The influence of estrus cycle on neurosteroid potency at the gammaaminobutyric acid A receptor complex. J Pharmacol Exp Ther 1993;265:1374-9.

Gamse R, Vaccaro DE, Gamse G, DiPace M, Fox TO, Leeman SE. Release of immunoreactive somatostatin from hypothalamic cells in culture: inhibition by $\gamma$ aminobutyric acid. Proc Natl Acad Sci USA 1980;77:5552-6.

Garcia R. Stress, hippocampal plasticity, and spatial learning. Synapse 2001;40:180-3.

Garcia-Segura LM, Chowen JA, Naftolin F. Endocrine glia: roles of glial cells in the brain actions of steroid and thyroid hormones and in the regulation of hormone secretion. Front Neuroendocrinol 1996;17:180-211.

Gibbs RB. Levels of trkA and BDNF mRNA, but not NGF mRNA, fluctuate across the estrous cycle and increase in response to acute hormone replacement. Brain Res 1998;787:259-68.

Givalois L, Marmigère F, Rage F, Ixart G, Arancibia S, Tapia-Arancibia L. Immobilization stress rapidly and differentially modulates BDNF and TrkB mRNA expression in the pituitary gland of adult male rats. Neuroendocrinology 2001;74:148-59.

Glass DJ, Yancopoulos GD. The neurotrophins and their receptors. Trends Cell Biol 1993;3:262-8.

Green PS, Simpkins JW. Neuroprotective effects of estrogens: potential mechanisms of action. Int J Develop Neurosci 2000;18:347-58.

Hashemi SH, Li JY, Schindler M, Dahlstrom A. Presence of sst2(a) receptor immunoreactivity in rat ependyma and tanycytes. NeuroReport 2001;12:1793-7.

Hatton GI. Emerging concepts of structure-function dynamics in adult brain: the hypothalamo-neurohypophysial system. Prog Neurobiol 1990;34:437-504.

Hatton GI. Function-related plasticity in hypothalamus. Annu Rev Neurosci 1997;20:375-97. Helboe L, Stidsen CE, Moller M. Immunohistochemical and cytochemical localization of 
the somatostatin receptor subtype sst1 in the somatostatinergic parvocellular neuronal system of the rat hypothalamus. J Neurosci 1998;18:4938-45.

Hisano S, Daikoku S. Existence of mutual synaptic relations between corticotropinreleasing factor-containing and somatostatin-containing neurons in the rat hypothalamus. Brain Res 1991;545:265-75.

Itoi K, Helmreich DL, Lopez-Figueroa MO, Watson SJ. Differential regulation of corticotropin-releasing hormone and vasopressin gene transcription in the hypothalamus by norepinephrine. J Neurosci 1999;19:5464-72.

Jacobson L, Sapolsky R. The role of the hippocampus in feedback regulation of the hypothalamic-pituitary-adrenocortical axis. Endocrine Rev 1991;12:118-34.

Jovanovic JN, Benfenati F, Siow YL, Sihra TS, Sanghera JS, Pelech SL, et al. Neurotrophins stimulate phosphorylation of synapsin I by map kinase and regulate synapsin I-actin interactions. Proc Natl Acad Sci USA 1996;93:3679-83.

Jovanovic JN, Czernik AJ, Fienberg AA, Greengard P, Sihra TS. Synapsins as mediators of BDNF-enhanced neurotransmitter release. Nat Neurosci 2000;3:323-9.

Kam K, Park Y, Cheon M, Son GH, Kim K, Ryu K. Effects of immobilization stress on estrogen-induced surges of luteinizing hormone and prolactin in ovariectomized rats. Endocrine 2000;12:279-87.

Karavolas HJ, Hodges DR. Neuroendocrine metabolism of progesterone and related progestins. In: Ciba Foundation Symposium, ed. Steroids and neuronal activity. Chichester: John Wiley \& Sons, 1990:22-55.

Kawakami S. Glial and neuronal localization of ionotropic glutamate receptor subunitimmunoreactivities in the median eminence of female rats: GluR2/3 and GluR6/7 colocalize with vimentin, not with glial fibrillary acidic protein (GFAP). Brain Res 2000;858:198-204.

Kelly M, Moss R, Dudley C. The effects of microelectrophoretically applied estrogen, cortisol and acetylcholine on medial preoptic-septal unit activity throughout the estrous cycle of the female rat. Exp Brain Res 1977;30:53-64.

Kernie SG, Liebl DJ, Parada LF. BDNF regulates eating behavior and locomotor activity in mice. EMBO J 2000;19:1290-300.

Kim JJ, Yoon KS. Stress: metaplastic effects in the hippocampus. Trends Neurosci 1998;21:505-9.

King JC, Letourneau RJ. Luteinizing hormone-releasing hormone terminals in the median eminence of rats undergo dramatic changes after gonadectomy, as revealed by electron microscopic image analysis. Endocrinology 1994;134:1340-51.

Kokaia Z, Bengzon J, Metsis M, Kokaia M, Persson H, Lindvall O. Coexpression of neurotrophins and their receptors in neurons of the central nervous system. Proc Natl Acad Sci USA 1993;90:6711-5.

Kokaia Z, Metsis M, Kokaia M, Bengzon J, Elmer E, Smith M-L, et al. Brain insults in rats induce increased expression of the BDNF gene through differential use of multiple 
promoters. Eur J Neurosci 1994;6:587-96.

Korneyev A, Guidotti A, Costa E. Regional and interspecies differences in brain progesterone metabolism. J Neurochem 1993;61:2041-7.

Leibrock J, Lottspeich F, Hohn A, Hofer M, Hengerer B, Masiakowski P, et al. Molecular cloning and expression of brain-derived neurotrophic factor. Nature 1989;341:149-52.

Levine JE, Ramirez VD. In vivo release of luteinizing hormone-releasing hormone estimated with push-pull cannulae from the mediobasal hypothalami of ovariectomized, steroidprimed rats. Endocrinology 1980;107:1782-90.

Levi-Montalcini R, Cohen S. Effects of the extracts of the mouse submaxillary glands on the sympathetic system of mammals. Ann N Y Acad Sci 1960;85:324-40.

Luo X, Kiss A, Makara G, Lolait SJ, Aguilera G. Stress-specific regulation of corticotropin releasing hormone receptor expression in the paraventricular and supraoptic nuclei of the hypothalamus in the rat. J Neuroendocrinol 1994;6:689-96.

Ma YJ, Junier MP, Costa ME, Ojeda SR. Transforming growth factor- $\alpha$ gene expression in the hypothalamus is developmentally regulated and linked to sexual maturation. Neuron 1992;9:657-70.

Marmigère F, Rage F, Tapia-Arancibia L, Arancibia S. Expression of mRNAs encoding BDNF and its receptors in adult rat hypothalamus. NeuroReport 1998;9:1159-63.

McAllister AK, Katz LC, Lo DC. Neurotrophins and synaptic plasticity. Annu Rev Neurosci 1999;22:295-318.

McEwen BS. Non-genomic and genomic effects of steroids on neural activity. Trends Pharmacol Sci 1991;12:141-7.

Melcangi RC, Martini L, Galbiati M. Growth factors and steroid hormones: a complex interplay in the hypothalamic control of reproductive functions. Prog Neurobiol 2002;67:421-49.

Mitsugi N, Arita J, Kimura F. Effects of intracerebroventricular administration of growth hormone-releasing factor and corticotropin-releasing factor on somatostatin secretion into rat hypophysial portal blood. Neuroendocrinology 1990;51:93-6.

Mosher K, Young D, Munck A. Evidence for irreversible, actinomycin D-sensitive, and temperature-sensitive steps following the binding of cortisol to glucocorticoid receptors and precoding effects on glucose metabolism in rat thymus cells. J Biol Chem 1971;246:654-9.

Nawa H, Carnahan J, Gall C. BDNF protein measured by a novel enzyme immunoassay in normal brain and after seizure: partial disagreement with mRNA levels. Eur J Neurosci 1995;7:1527-35.

Neumann I, Ludwig M, Engelmann M, Pittman QJ, Landgraf R. Simultaneous microdialysis in blood and brain: oxytocin and vasopressin release in response to central and peripheral osmotic stimulation and suckling in the rat. Neuroendocrinology 1993;58:637-45.

Ojeda SR, Dissen GA, Junier MP. Neurotrophic factors and female sexual development. 
Front Neuroendocrinol 1992;13:120-62.

Ono N, Samson WK, McDonald JK, Lumpkin MD, Bedran de Castro JC, McCann SM. Effects of intravenous and intraventricular injection of antisera directed against corticotropin-releasing factor on the secretion of anterior pituitary hormones. Proc Natl Acad Sci USA 1985;82:7787-90.

Paul SM, Purdy RH. Neuroactive steroids. FASEB J 1992;6:2311-21.

Pelleymounter MA, Cullen MJ, Wellman CL. Characteristics of BDNF-induced weight loss. Exp Neurol 1995;131:229-38.

Pioro EP, Cuello AC. Distribution of nerve growth factor receptor-like immunoreactivity in the adult rat central nervous system. Effect of colchicine and correlation with the cholinergic system-I. Forebrain. Neuroscience 1990;34:57-87.

Prevot V. Glial-neuronal-endothelial interactions are involved in the control of GnRH secretion. J Neuroendocrinol 2002;14:247-55.

Prevot V, Croix D, Bouret S, Dutoit S, Tramu G, Stefano GB, et al. Definitive evidence for the existence of morphological plasticity in the external zone of the median eminence during the rat estrous cycle: Implication of neuro-glio-endothelial interactions in gonadotropin-releasing hormone release. Neuroscience 1999;94:809-19.

Prieto M, Chauvet N, Alonso G. Tanycytes transplanted into the adult rat spinal cord support the regeneration of lesioned axons. Exp Neurol 2000;161:27-37.

Purdy RH, Morrow AL, Moore PH, Paul SM. Stress-induced elevations of $\boldsymbol{\gamma}$-aminobutyric acid type A receptor-active steroids in the rat brain. Proc Natl Acad Sci USA 1991;88:4553-7.

Rage F, Benyassi A, Arancibia S, Tapia-Arancibia L. $\boldsymbol{\gamma}$-aminobutyric acid-glutamate interaction in the control of somatostatin release from hypothalamic neurons in primary culture: in vivo corroboration. Endocrinology 1992;130:1056-62.

Rage F, Givalois L, Marmigère F, Tapia-Arancibia L, Arancibia S. Immobilization stress rapidly modulates BDNF mRNA expression in the hypothalamus of adult male rats. Neuroscience 2002;112:309-18.

Rage F, Jalaguier S, Rougeot C, Tapia-Arancibia L. GABA inhibition of somatostatin gene expression in cultured hypothalamic neurons. NeuroReport 1993;4:320-2.

Rage F, Riteau B, Alonso G, Tapia-Arancibia L. Brain-derived neurotrophic factor and neurotrophin-3 enhance somatostatin gene expression through a likely direct effect on hypothalamic somatostatin neurons. Endocrinology 1999;140:909-16.

Ramirez VD. The push-pull perfusion technique in neuroendocrinology. In: Bayon A, Drucker-Colin R, eds. In vivo perfusion and release of neuroactive substances. NewYork: Academic Press, 1985:249-76.

Rios M, Fan G, Fekete C, Kelly J, Bates B, Kuehn R, et al. Conditional deletion of brainderived neurotrophic factor in the postnatal brain leads to obesity and hyperactivity. Mol Endocrinol 2001;15:1748-57.

Rivier C, Vale W. Involvement of corticotropin-releasing factor and somatostatin in stress- 
induced inhibition of growth hormone secretion in the rat. Endocrinology 1985;117:2478-82.

Robel P, Baulieu EE. Neurosteroids: biosynthesis and function. Trends Endocrinol Metab 1994;5:1-8.

Rupprecht R, Reul JMHM, Trapp T, van Steensel B, Wetzel C, Damm K, et al. Progesterone receptor-mediated effects of neuroactive steroids. Neuron 1993;11:523-30.

Scharfman HE, Goodman JH, Sollas AL. Actions of brain-derived neurotrophic factor in slices from rats with spontaneous seizures and mossy fiber sprouting in the dentate gyrus. J Neurosci 1999;19:5619-31.

Schwartz RD, Weiss MG, Labarca R, Skolmick P, Paul SM. Acute stress enhances the activity of the GABA receptor-gated chloride ion channel in brain. Brain Res 1987;411:151-5.

Shors TJ, Dryver E. Effect of stress and long-term potentiation (LTP) on subsequent LTP and the theta burst response in the dentate gyrus. Brain Res 1994;666:232-8.

Smith MA, Makino S, Kim SY, Kvetnansky R. Stress increases brain-derived neurotrophic factor messenger ribonucleic acid in the hypothalamus and pituitary. Endocrinology 1995;136:3743-50.

Smith MA, Zhang LX, Lyons WE, Mamounas LA. Anterograde transport of endogenous brain-derived neurotrophic factor in hippocampal mossy fibers. NeuroReport 1997;8:1829-34.

Sohrabji F, Miranda RCG, Toran-Allerand CD. Identification of a putative estrogen response element in the gene encoding brain-derived neurotrophic factor. Proc Natl Acad Sci USA 1995;92:11110-4.

Solum DT, Handa RJ. Estrogen regulates the development of brain-derived neurotrophic factor mRNA and protein in the rat hippocampus. J Neurosci 2002;22:2650-9.

Tannenbaum GS, Epelbaum J, Cole E, Brazeau P, Martin JB. Antiserum to somatostatin reverses starvation-induced inhibition of growth hormone but not insulin secretion. Endocrinology 1978;102:1909-14.

Terry LC, Willoughby JO, Brazeau P, Martin JB, Patel Y. Antiserum to somatostatin prevents stress-induced inhibition of growth hormone secretion in the rat. Science 1976;192:565-7.

Thoenen H. Neurotrophins and neuronal plasticity. Science 1995;270:593-8.

Timmusk T, Palm K, Metsis M, Reintam T, Paalme V, Saarma M, et al. Multiple promoters direct tissue-specific expression of the rat BDNF gene. Neuron 1993;10:475-89.

Toran-Allerand CD, Miranda RC, Bentham WD, Sohrabji F, Brown TJ, Hochberg RB, et al. Estrogen receptors colocalize with low-affinity nerve growth factor receptors in cholinergic neurons of the basal forebrain. Proc Natl Acad Sci U S A 1992;89:466872.

Vale W, Rivier C, Brazeau P, Guillemin R. Effects of somatostatin on the secretion of thyrotropin and prolactin. Endocrinology 1974;95:968-77. 
Watts AG. The impact of physiological stimuli on the expression of corticotropin-releasing hormone (CRH) and other neuropeptides genes. Front Neuroendocrinol 1996;17:281-326.

Wilson MA, Biscardi R. Sex differences in GABA/benzodiazepine receptor changes and corticosterone release after acute stress in rats. Exp Brain Res 1994;101:297-306.

Yan Q, Matheson C, Sun J, Radeke MJ, Feinstein SC, Miller JA. Distribution of intracerebral ventricularly administered neurotrophins in rat brain and its correlation with trk receptor expression. Exp Neurol 1994;127:23-36.

Zorilla R, Simard J, Labrie F, Pelletier G. Variation of pre-pro-somatostatin mRNA levels in the periventricular nucleus during the rat estrous cycle. Mol Cell Neurosci 1991;2:294-8.

Zorilla R, Simard J, Rhéaume E, Labrie F, Pelletier G. Multihormonal control of preprosomatostatin mRNA levels in the periventricular nucleus of the male and female rat hypothalamus. Neuroendocrinology 1990;52:527-36. 